
Manuelzão nasceu num lugarejoobscuro e isolado no sertão de Minas Gerais. Seu pai era um humilde trabalhador rural, em situação de extrema pobreza. Conformado a esse estado, o pai condena a família ao confinamento num círculo de miséria. Essa imagem de vida sitiada é sugerida pela configuração geográfica de onde nasceu Manuelzão, um lugar de gente muito pobre, que vivia numa planície rodeada de montanhas. A própria forma gráfica do nome desse lugar - MIM - funciona como um ícone, que representa o indivíduo, "I", emparedado pelos montanhosos "MM". Note-se que o topônimo em questão é um palíndromo, o que reforça a sugestão de confinamento sem saída. Também não se pode esquecerque, gramaticalmente, "mim" é um pronome pessoal, forma oblíqua de "eu". Tudo isso sugere, obliquamente, que o "eu” (Manuelzão), nascido em Mim, estaria fadado a repetir a mesma sina de seu pai se não ultrapassasse os limites de sua condição original.

Mas Manuelzão, ao contrário do pai, que era trabalhador de enxada, não se conformou com a perspectiva de reproduzir a mesma existência obscura. Rompendo com o imobilismo de sua origem, escolheu a profissão de vaqueiro, que, por natureza, se caracteriza pela extrema mobilidade. Abandonando o Mim, Manuelzão parte em busca de uma nova identidade.

Embora herde do pai a ética da vida dedicada a trabalho, o protagonista se opõe à figura paterna à medida que ultrapassa os limites geográficos de Mim e, ao contrário do pai agricultor, sempre fixo no mesmo lugar, ganha o mundo sem fronteiras, na condição de vaqueiro.

Num primeiro momento, essa oposição entre fixidez e mobilidade é radical. O filho torna-se um errante, empregado em fazendas diversas, mundo afora, livre e só, até chegar às portas da velhice; num segundo momento, perto dos 60 anos, Manuelzão reproduz algo do exemplo paterno ao constituir família.

Convidado pelo capitalista Federico Freyre, o experiente vaqueiro desloca-se

\section{JOSÉ DE PAULA}

RAMOS JR. é

doutorando em Literatura Brasileira na USP e autor de Sondas (Ateliê).

ao extremo do sertão explorado de Minas Gerais para formar uma nova fazenda, onde interromperia o ciclo da experiência nômade. É quando ele sente que, "para fundar lugar, lhe faltava o necessário de alguma espécie" (p. 548). Para suprir essa falta ele chama para a Samarra o filho, Adelço de Tal, que tivera numa relação casual e com quem nunca convivera. Adelço leva a mulher Leonísia e sete filhos. Manuelzão manda buscar também a velha mãe, dona Quilina, e, assim, inventa, de repente, uma família para si.

Ao se fixar num lugar - a Samarra - e constituir família, Manuelzão reproduz a experiência paterna, mas num nível superior ao vivenciado por seu pai. Dialeticamente, Manuelzão nega, conserva e supera o pai: nega, ao sair de casa e tornar-se vaqueiro; conserva, ao fixar-se na Samarra e constituir família; supera, ao tornar-se o "único dono visível” (p. 546) da Samarra. Dono. Seu nome passa a ser largamente conhecidoe respeitado, ao contrário do pai, que nada tivera na vida, a não ser a sua força de trabalho, que morrera no mais obscuro anonimato.

E interessante notar que, no momento culminante de sua vida, o herói modifica o seu nome. “'Manuel Jesus Rodrigues' - Manuelzão J. Roiz -: gostaria pudesse ter escrito também, debaixo do título da Santa, naquelas bonitas letras azuis, com o resto da tinta que, não por pequeno preço, 
da Pirapora mandara vir. Queria uma festa forte, a primeira missa. Agora, por dizer, certo modo, aquele lugar da Samarra se fundava" (p. 544). O rito religioso e festivo de fundação do lugar coincide com a mudança de identidade do herói, que ultrapassa a condição de sua origem subalterna para tornar-se senhor e dono.

Apesar da posição alcançada, Manuelzão experimenta o desconfortável sentimento de incompletude e precariedade de sua situação. Ele sente que não é dono, propriamente, da Samarra, mas um "administrador, quase sócio, meio capataz de vaqueiros, certo um empregado" (p. 546). A consciência disso o inquieta; ele sente que só a riqueza poderia trazer alguma segurança: "ficar rico era o que era seguro. Rico, para não precisar de se ter medo de que todo o pouco que fosse da gente não estivesse sempre salteado" (p. 574).

Para alcançar a riqueza, no entanto, ele pressente que sua vida seria insuficiente, que alguém deveria dar continuidade ao seu esforço. Principalmente, porque, perto dos 60 anos de idade, começara a sentir certos sintomas, que o levavam a pensar na morte. Essas circunstâncias é que o motivaram a reunir uma família no outono de sua vida. "Carecia de um filho prosseguinte. Um que levasse tudo levantado, sem deixar o mato rebrotar" (p. 567). Porém, Manuelzão não acreditava que Adelço fosse essa pessoa.

Há uma nítida oposição entre pai e filho, que se configura em duas instâncias. Primeiramente, aos olhos de Manuelzão, Adelço parece demais com o avô, de quem ele, Manuelzão, fora a antítese. Adelço, identificando-se com o avô, seria para Manuelzão, em termos lógicos, a negação da negação. "Não o Adelço - ele sabia que o Adelço não tinha esse valor. Doía de se conhecer: que tinha um filho, e não tinha. Mas esse Adelço saíra triste ao avô, ao pai dele Manuelzão, que lavrava rude mas só de olhos no chão, debaixo do mando de outros, relambendo sempre seu pedacinho de pobreza, privo de réstia de ambição de vontade. Desgosto..." (p. 567).

O narrador enfatiza, em outra passagem, que o desgosto maior decorria da omissão do filho em relação a certos deveres tácitos, como o de estar presente em alguns momentos relevantes da grande festa que marcava a fundação da Samarra e, especialmente, o de se oferecer para tocar uma boiada, após os festejos, em seu lugar, justamente quando ele, Manuelzão, se sentia frágil e nutria fantasias de morte. Manuelzão sente raiva de Adelço porque este não demonstra a consideração que se deve, se não aos pais, aos superiores.

No livro II da Retórica, Aristóteles assinala que as paixões são "todos aqueles sentimentos que mudam e afetam os juízos dos homens, e que são também acompanhados por dor ou prazer" (4). No caso em questão, o sentimento que afeta o juízo negativo de Manuelzão quanto ao filho é a ira, que, para Aristóteles, “pode ser definida como um impulso, acompanhado por dor, para uma manifesta vingança por causa de uma manifesta e injustificável desconsideração dirigida a uma pessoa ou a algum amigo dela" (5).

Para Aristóteles, o motivo fundamental da ira é a desconsideração, que é exatamente a causa, percebida por Manuelzão, desencadeadora de sua cólera. Mas é preciso deixar bem clara a situação em que a raiva se apodera do protagonista para se ter uma imagem mais nítida da coesão que há entre as postulações teóricas de Aristóteles e as disposições práticas, concernentes ao assunto, de Guimarães Rosa.

Resumindo, Manuelzão se encontra num momento decisivo de sua existência. Depois de uma longa jornada, desde a infância à sombra da miséria, desde a juventude de vaqueiro livre, no limiar da velhice, já pressentindo a morte, ele se vê na contingência de tornar-se senhor. Trata-se de uma mudança crucial, que lhe traz um sentimento misto de orgulho e insegurança de sua nova condição. Essa insegurança se acentua com a suposição de que Adelço desdenha a festa e o seu significado, além de não dar importância aos achaques que ele sentia (6), visto que não se dispunha a tocar a boiada em seu lugar. Na imaginação do velho vaqueiro, o comportamento omisso 
do filho é uma manifesta desconsideração à sua pessoa.

O desprezo, tal como Aristóteles assinala, é uma forma de desconsideração, que consiste em não se dar valor àquilo que é valorizado por outrem. É oque se dá nocaso do suposto desdém de Adelço para com a festa, que tem a máxima importância para Manuelzão, pois significa o reconhecimento de sua superioridade como fundadore "dono visível" da Samarra.

Acólera de Manuelzão é particularmente intensa porque ele se sente desprezado por quem se beneficiara de sua benevolência, que lhe deve respeito e que lhe é inferior em poder e em riqueza. Exatamente como descreve Aristóteles, a paixão da ira é acompanhada de dor, que é mais intensamente sofrida quando o desprezo vem de alguém próximo, de quem esperaríamos tratamento oposto (7). A dor decorre da desconsideração de que Manuelzão se sente vítima, supostamente praticada por quem lhe devia respeito por sua posição de superioridade, quer como pai, quer como patrão.

O desprezo injustificado de Adelço, percebido como tal por Manuelzão, é a causa da ira deste, do modo como Aristóteles demonstra que essa paixão é desencadeada nas pessoas. E nem falta à cólera do velho vaqueiro o sentimento de prazer que, segundo o filósofo, a acompanha. No caso, o prazer se manifesta nas fantasias de vingança (8) nutridas por Manuelzão. Com raiva do filho, ele sente prazer ao imaginar, como vingança, mandá-lo conduzir a boiada em seu lugare, em seguida, despachá-lo para mais longe da mulher Leonísia, afirmando assim seu sentimento de superioridade:

“Mesmo, por um capricho legal, não estava no poder de mandar aumentado? Assim: que, depois da boiada entregue, ainda o Adelço carecesse de ir para adiante, mais longe, mais tempo - levar por exemplo um bilhete, em mão, na Sete-Lagoas, no Belorizonte, no lugarejo do Mim, na Uberaba! - então tinha de passar não era um mês, não, mas dois, três, seis meses, sei lá, longe da Leonísia. Pra ver o que é bom..." (p. 568).

\section{AMOR}

A segunda instância da oposição entre Manuelzão e Adelço envolve a nora Leonísia. E aqui se encontra a chave que ajuda a entender melhor o título da novela. Aparentemente, a história de amor a que se refere o título diz respeito ao vínculo afetivo que une as personagens de dois contadores de histórias, que são envolvidos numa trama paralela ao eixo narrativo principal, o velho Camilo e Joana Xaviel. Isso se levarmos em conta somente o que o narrador insiste em explicitar:

- "De sombra, se vislumbrava que a Joana, sua parte, dele velho Camilo não fazia pouco-caso. Olhos que olhava, parecia que parecia. Às dãs! Remedavam namoro? Acontecia isso?" (p. 584)

- "A Joana Xaviel devia de estar agora no meio dos cantadores, aceitando graças de homem, quem sabe. Ou, então, era só o penar de não residirem mais juntos, na cafua da chapada. Velho assim não podia gostar de mulher?" (pp. 592-3)

- "O velho Camilo, soturno. Rabujava? Bebeu ofel-vinagre? Podia perguntar:-Seo Camilo, está mal com alguém? Sendo de soer: os agastamentos com a Joana Xaviel - Uma estória de amor. A graça!” (p. 596)

Se essa for a história de amor destacada pelo título, então, a novela frustra a expectativa dos leitores. O narrador leva o leitor a pensar que se trata do amor dos dois contadores de histórias, mas não dá solução para esse relacionamento, cujo desenlace permanece aberto. O par não ata nem desata. A própria enunciação duvida dessa história de amor: "Mas tinha lá alguma graça aquela estória de amor nessas gramas ressequidas, de um velhão no burro baio com uma bruaca assunga-a-roupa?" (p. 573)

No subterrâneo da história, porém, insinua-se um outro caso de amor. Um amor ilícito.

A ojeriza que Manuelzão nutre pelo filho apresenta um viés psicológico complicado. Como vimos, Manuelzão antipatiza

\footnotetext{
Aristóteles, op. cit., p. 624 "[...] a man looks for respect from those who he thinks owe him good treatment, and these are people whom he has treated or is treating well. [...] we are angrier with our friends than with other people, since we feel that our friends ought to treat us well and not badly". I"Um homem exige respeito daqueles que ele julga deveremthe bom tratamento, e essas são as pessoas que ele tratou ou está tratando bem. [...] nós nos encolerizamos mais com os amigos do que com outras pessoas, visto que, conforme pensamos, nossos amigos têm a obrigação de nos tratar bem e não mal.") A amizade é aqui entendida no sentido de philia que inclui entre as suas espécies as relações de parentesco e as de dependência dos que não possuem laços de sangue com o superior (ver nota 8).

8 Aristóteles, op. cit., p. 624 "[...] [anger] is also attended by a certain pleasure because the thoughts dwell upon the act of vengeance, and the images then called up cause pleasure like the images called up in dreams.". "[...][a ira] é também acompanhada por um certo prazer porque os pensamentos antecipam o ato de vingança eas imagens invocadas causam prazer, como as imagens evocadas em sonhos.")
} 
com Adelço pela semelhança deste com o avô. A antipatia do velho vaqueiro faz com que ele quase só veja defeitos no filho, a quem avalia como um homem "mesquinho e fornecido maldoso, um homem esperando para ser ruim [...], um sujeito assim, desamigo de todos" (pp. 548-9). Manuelzão só não chegou a mandar Adelço embora da Samarra por causa de Leonísia.

Se a opinião que Manuelzão tem do filho é muito ruim, a que ele tem da nora é a melhor possível. A beleza da nora é frequientemente notada pelo sogro, que exalta também suas qualidades morais, a ponto de defini-la como uma mulher "boa, uma sinhá exata, só senhora. [...] tinha sinal de um sabido anjo-da-guarda" (p. 549).

Manuelzão considera Adelço desmerecedor da mulher que tem, e chega a ter inveja, ciúme e "maus pensamentos":

“Leonísia já devia de estar em cama, junto com o Adelço, só ele tinha direito de olhar a formosura alegre de Leonísia. Mesmo de pensar, mesmo de reparar no rosto, no descanso de Leonísia. Deus de lei. Maus pensamentos. A Leonísia devia de ter permanecido sempre exata donzela formosa, não se casado com ninguém” (p. 571).

O desejo proibido, recalcado no íntimo, aflora, mas é logo disciplinado por um escrúpulo moral que redireciona a mira do desejo para um alvo abstrato: uma mulher hipotética, que se assemelhasse à nora: “Não dava para o amor. Por certo ainda podia se casar, tinha forças e parecer para isso? Soubesse de achar uma moça da igualha de formosura, da simpatia de Leonísia, sim, casava" (p. 573).

É importante dizer que o comportamento de Leonísia não encoraja os "maus "Friendship has various forms - comradeship, intimacy, kinship, and so on". I"A amizade tem várias formas - camaradogem, intimidade, parentesco e assim por diante.")

10 Aristóteles, "Ética a Nicômaco", in Os Pensadores, São Paulo, Abril, 1973, pp. 379 e seg.
"Jantar, se jantava. Manuelzão não tinha fome nenhuma. Tomou um gole de café, outro gole de aguardente; pitou um cigarro. A cozinha, confusa de mulheres. Parava ali, lerdeando, estadonho. Tempão, que estava. Atinando - queria ver Leonísia. Requeria alguma palavra de estima, de consolo? Que era que se envelhecia? Mas, quando Leonísia com ele defrontou, deu má surpresas, nos olhos que abriu, mesmo no dizendo, com aquela voz escolhida de gentil: - 'Pai, o que o senhor está sentindo? A não está bem? Não estou gostando dessa sua cor, isso é cansaços da festa, tamanha lufa. O senhor preza um chá?' Não. Que estava subido de bem. Era o que ele garantia. Leonísia era de beira do Grotão do Abaeté, de que família que na roda do tempo havia podido ajuntar tantas canduras? Assim aprazível de coração, assisada uma filha" (pp. 593-4, grifo meu).

Assim, afastam-se as nuvens do amor suspeito. Fica transparente ao próprio Manuelzão o caráter paternal de seu amor por Leonísia. Trata-se, portanto, de uma espécie de amor definida por Aristóteles, na Retórica (9) e na Ética a Nicômaco (10), como philia.

Será essa, então, a história de amor? Ada descoberta do amor paterno de Manuelzão? Suspeitamos que sim, mas não exatamente em relação à nora. A nossa hipótese é de que a história de amor, destacada no título da novela, é, sobretudo, a história do amor paterno de Manuelzão, mas, mais propriamente, do amor pelo filho Adelço.

Isso pode parecer estranho, com tantos índices de desamor disseminados na narrativa. Mas é importante notar que o caráter negativo de Adelçoé desenhado na perspectiva de Manuelzão. Não se tem acesso à opinião de outras personagens. Deduz-se que a de Leonísia seja bem diferente, pois ela em momento algum se queixa do que quer que seja. Por meio das próprias observações de Manuelzão, que reconhece a reciprocidade de afeto entre marido e mulher, presume-se que ela seja feliz no casamento: "Ela, para o Adelço, era a melhor companheira. Sina de mulher, sina de homem" (p. 594). Dona Quilina, que "reconhecia o tamanho da alma 
de toda pessoa, no disparo de um olhar" ( $\mathrm{p}$ 562), nada diz a propósito do neto.

Quanto ao narrador, sua opinião coincide, aparentemente, com a de Manuelzão, mas ela é suspeita, em virtude da manifesta postura empática que mantém com o protagonista da história. Apesar dessa empatia, porém, o narrador não deixa de registrar indícios que podem corrigir uma impressão desfavorável a Adelço. O próprio Manuelzão, reiteradamente, enfatiza a disposição do filho para o trabalho, que, no código de valores do velho vaqueiro, é a virtude maior. Também é destacada a dedicação votada por Adelço aos filhos e, como já vimos, à mulher.

Quando o vaqueiro atribui a desconsideração do filho ao exagerado apego com a esposa, pode parecer ciúme que ele sente de Leonísia, mas pode-se entender que, no fundo, é ciúme de Adelço, pois, afinal, o manifesto apreço por mulher e filhos contrasta com a desconsideração sentida por Manuelzão, que, apesar de tudo, é o pai de Adelço. Manuelzão se sente rejeitado pelo filho.

Em favor de Adelço, é preciso dizer ainda que o narrador assinala sua presença em vários daqueles momentos relevantes, dos quais Manuelzão o julgava alheio: dentro da igreja, na hora da missa; desdobrando-se para atender aos convidados ilustres, numa hora de esmorecimento da festa.

Quando Adelço, inesperada e publicamente, se aproxima de Manuelzão e se oferece para conduzir a tal boiada, com sinal evidente de consideração pela saúde e respeito pela pessoa do pai, a má impressão que se tem do moço se desvanece prontamente.

Manuelzão já sentia um desconforto moral por não gostar do filho: "Mesmo achava, devia gostar do Adelço; mas ainda não conseguia reunido, na prática. Tencionou; pelejava. O Adelço teria ódio a ele?" (p. 574). O gesto do filho demonstra que não havia ódio, mas respeito e consideração. Com isso, a imagem negativa atribuída a Adelço se converte em seu oposto, ou seja, Adelço se torna a imagem do bom filho. Manuelzão, internamente, exulta de alegria paterna - "Manuelzão pôs bem o peito, dos ombros, nas pressas de um sentir, como, de supetão, demais se felicitava" (p. 600).

A surpresa da proposta generosa de Adelço faz o velho vaqueiro pensar. Ele entende que não poderia culpar o filho pelos problemas dele, Manuelzão, como fizera até o momento. Sente-se envergonhado, faz um rápido balanço de sua situação na vida, pensa nos sintomas que o afligiam e na possibilidade da morte próxima, para concluir: "Faço e faço, mas não tem outro jeito: não vivo encalcado, parece que estou num erro [...]. Assim o que a gente quer, e o querer não fica em pé, mas se desvém no ar" (p. 601).

Em outros termos, Manuelzão filosofa sobre o sentido da ação e da vontade dos homens; em última análise, sobre o desconcerto e a falta de sentido da vida. Como não consegue encontrar resposta satisfatória às suas questões, pensa em consultar o velho Camilo, mas, em vez disso, num impulso, manda que ele conte uma história.

Essa história, narrada pelo velho Camilo no fim da festa, tem o misterioso condão de revelar o sentido da existência e de, finalmente, libertar os sentimentos reprimidos de Manuelzão, que, comovido, se abraça com o filho e a nora, em frente aos amigos irmanados no sentimento de camaradagem. O fato de essa cena se apresentar como clímax da novela reforça a idéia de que a "estória de amor" destacada no título é, sobretudo, a do problemático amor do pai pelo filho. A paixão do amor, nesse contex to que envolve relações de parentesco e de camaradagem, aproxima-se claramente da noção aristotélica de philia.

Manuelzão é um herói fundador de lugar, que, no ato de fundação, assume a superior condição de único "dono visível" da Samarra. A festa inaugural da fazenda celebra o reconhecimento dessa superioridade, que se afirma nas demonstrações de respeito da família e da sociedade sertaneja. Nessa medida, a narrativa pode ser vista como história da instauração da philia de Manuelzão e de sua posição de destaque nessa comunidade de parentes e de amigos, isto é, de seu poder. 


\section{DIÁLOGO DE ROSA COM ARISTÓTELES}

Como dissemos na abertura deste texto, as observações de Aristóteles sobre as emoções são indissociáveis do contexto que as gerou. No entanto, suas considerações se mostram válidas e até mesmo indispensáveis na análise de uma obra literária contemporânea, como é o caso de "Uma Estória de Amor", de Guimarães Rosa. Pudemos observar o alto grau de coesão que se estabelece entre a teoria do filósofo e a prática do artista. É certo que há diferenças que uma análise mais extensa poderia apontar. Mas isso não invalida as semelhanças explicitadas em nossa discussão, posto que elas se impõem como evidências.

Como explicar essa congruência entre autores de épocas e propósitos tão diversos? Seria a essência do homem do passado aristotélico fundamentalmente idêntica à do homem do presente rosiano? Para Guimarães Rosa, pelo que se sabe de suas convicções metafísicas, provavelmente, sim. Mas não nos interessa, no limite modesto deste trabalho, desenvolver essa questão ontológica. Basta-nos a constatação óbvia de que as formulações aristotélicas geraram uma tradição ilustre que, ao longo de diferentes épocas, foi aproveitada por inúmeros escritores, e que se consubstancia de modo inequívoco na novela "Uma Estória de Amor".

Nessa obra, evidencia-se um diálogo entre os dois autores, cujas noções de ira e de amor (philia) apresentam a coesão que buscamos salientar na comparação dessas paixões, tal como são desenhadas pelo artista e pelo filósofo. Aqui importa menos se a fonte aristotélica é direta ou indiretamente absorvida, embora fique a impressão de que Guimarães Rosa construiu as referidas paixões de sua personagem seguindo de perto a lição do livro II da Retórica. Tratase de uma evidente apropriação da teoria aristotélica como fonte de criação literária contemporânea.
Guimarães Rosa soube incorporar organicamente a teoria do filósofo à sua arte. Não há nada de mecânico na apropriação, tal a naturalidade com que as emoções se desenvolvem no espírito da personagem, de acordo com a descrição aristotélica e, o que talvez surpreenda, de acordo com a sensibilidade contemporânea. A análise comparativa dessas emoções, nas referidas obras de Rosa e de Aristóteles, demonstra que as formulações do filósofo são válidas na composição de caracteres literários que mimetizam ou constroem artisticamente as paixões humanas hodiernas, embora inseridas num ambiente em que há muito de arcaico, como é o sertão mineiro representado na narrativa. É importante assinalar que a mimese produzida por Guimarães Rosa apresenta aquela verossimilhança fundamental para a validação de uma obra de arte, como o próprio Aristóteles aponta na Poética. E, para a nossa análise, é mais importante ainda frisar que se trata da verossimilhança de uma obra literária contemporânea, que pressupõe uma sensibilidade contemporânea na sua recepção.

O passado grego é incorporado ao presente do sertão brasileiro, que, para Guimarães Rosa, representa o mundo. Trata-se do universalismo regionalista, ou regionalismo metafísico, que a crítica geralmente atribui ao autor de Grande Sertão: Veredas.

Mas, resguardada a hipótese da identidade essencial dos homens de épocas e lugares distintos, numa perspectiva analítica diacrônica, histórica, identificar as paixões da Antiguidade com as da nossa contemporaneidade seria um anacronismo. Esse problema talvez pudesse ser resolvido com a análise das diferenças, de que não nos ocupamos aqui. Essa análise, porém, poderia configurar melhor o caráter dialético da assimilação rosiana das considerações de Aristóteles a propósito das paixões, mas esse não é o escopo deste trabalho, que se dá por satisfeito com a demonstração de um caso modelar de sobrevivência "clássica" na expressão das emoções na literatura contemporânea. 